\title{
A COMPLEX PROPORTIONAL ASSESSMENT METHOD FOR GROUP DECISION MAKING IN AN INTERVAL-VALUED INTUITIONISTIC FUZZY ENVIRONMENT
}

\author{
Seyed Hossein RAZAVI HAJIAGHA a, Shide Sadat HASHEMI ${ }^{\mathrm{b}}$, \\ Edmundas Kazimieras ZAVADSKAS ${ }^{c}$ \\ a, Institute for Trade Studies and Research, Sheibani Alley, North Jamalzade Ave., Tehran, Iran \\ ${ }^{\mathrm{c}}$ Faculty of Civil Engineering, Vilnius Gediminas Technical University, \\ Sauletekio al. 11, LT-10223Vilnius, Lithuania
}

Received 28 June 2012; accepted 09 September 2012

\begin{abstract}
Multi-criteria decision making is an implicational field that concerns with selecting or designing the best scenarios among a finite set of scenarios based on a finite set of criteria. Different methods and techniques for handling this issue have been proposed. Complex proportional assessment is an analytical tool for solving multi-criteria decision making problems. Originally, the COPRAS method has been developed for decision making under a deterministic environment. Since uncertainty is an unavoidable property of decision making due to a lack of knowledge, this paper suggests an extended form of the COPRAS method used for group decision making problems in an uncertain environment where such uncertainty is captured through a generalized form of fuzzy sets - the so called interval valued intuitionistic fuzzy sets. An algorithmic scheme for the COPRAS-IVIF method has been introduced thus examining its application with reference to two numerical examples. It seems that the recommended framework of COPRAS-IVIF can be satisfactorily implemented in decision making problems under ambiguous and ill-defined conditions.
\end{abstract}

Keywords: multiple criteria decision making, uncertainty, COPRAS, interval valued intuitionistic fuzzy sets.

Reference to this paper should be made as follows: Razavi Hajiagha, S. H.; Hashemi, Sh. S.; Zavadskas, E. K. 2013. A complex proportional assessment method for group decision making in an interval-valued intuitionistic fuzzy environment, Technological and Economic Development of Economy 19(1): 22-37.

JEL Classification: C02, C44, G32. 


\section{Introduction}

Multiple criteria decision making (MCDM) is an applicable branch of operation research which means 'decision making considering multiple affecting criteria'. This class is further divided into multi-objective decision making and multi-attribute decision making (MADM) (Climaco 1997). The problem of MADM often arises when the issue of a choice or comparison emerges. Due to frequent numerous and antithetic criteria established dealing with actual decision making problems, MCDM methods have become one of the most commonly used branches of operation research science during last decades (Triantaphyllou 2000; Figueira et al. 2005; Zavadskas, Turskis 2011; Antucheviciene et al. 2011; Kou et al. 2012; Bragge et al. 2012). A formal definition of the MADM problem can be stated as follows: Suppose that we have a nonempty and finite set of decision alternatives, that their desirability will be judged according to a finite set of goals, attributes or criteria. The aim of MADM is to determine an optimal alternative having the highest degree of desirability with respect to all relevant goals (Zimmerman 1987). Hwang and Yoon (1995) categorized MADM techniques as two compensatory and non-compensatory models. A compensatory class allows interchange among criteria. Compensatory models themselves fall into three main subgroups: scoring sub-models, a compromising subgroup and a concordance subgroup.

Each method of MADM can be classified into deterministic and indeterministic methods. The challenge of uncertainty in decision making is the provenance of such classification. Uncertainty is frequently an output of the unfamiliarity of decision makers with alternatives or their situation regarding different criteria. In fact, most of decisions are not made on the basis of the well-known calculations and there is much ambiguity and uncertainty in decision making problems (Riabacke 2006). Under these conditions, exact data are inadequate to model real-life problems. In response to such complexity and ambiguity, some researchers suggest the application of structures such as fuzzy sets and grey numbers in decision making. The fuzzy set theory, introduced by Zadeh (1965), is the generalization of the classic set theory that assigns a single membership degree (function) to each element. Grattan-Guinness (1976) discovered and later Gau and Buehrer (1993) pointed out that the presentation of a linguistic expression in the form of a fuzzy set was not enough. Atanassov (1986) introduced the notion of an intuitionistic fuzzy set (IFS) as the generalization of Zadeh's fuzzy sets. In addition to the membership degree of each element in ordinal fuzzy sets, the IFS assigns a degree of non-membership to each element. Later, Atanassov and Gargov (1989) extended it to an interval valued intuitionistic fuzzy set (IVIFS). The IFS and IVIFS have wide applications to analyze problems with uncertainty, including questions related to MADM.

Li (2005) investigated MADM using the IFS and proposed a method for decision making in such environment. Li (2008) further developed linear programming techniques for multidimensional analysis of preference (LINMAP) under the IFS presented by Atanassov. Li et al. (2009) and Boran et al. (2009) adopted the TOPSIS method under the IFS. Li (2010a) generalized OWA aggregation operators for the IFS and developed a method for MADM. Verma et al. (2010), Ye (2010) and Park et al. (2011) promoted the TOPSIS method under the IVIFS. Li (2010b) worked out a methodology for solving MADM problems. The ratings of alternatives for both attributes and weights are expressed using the IVIFS. Xu (2012) investigated MADM problems when attribute values were the IFS. Vahdani et al. (2012) 
improved the ELECTRE method for group MADM based on the IFS. Chen et al. (2012) proposed a MADM method based on the IVIFS weighted averaging operator and a fuzzy ranking method for the IFS.

The Complex Proportional Assessment (COPRAS) method as a new method of MADM was suggested by Zavadskas et al. (1994). The COPRAS method determines a solution and the ratio to the ideal solution and the ratio to the worst-ideal solution, and therefore can be regarded as a compromising method. The COPRAS method is applied for solving numerous problems by its exhibitors and their colleagues. Andruškevicius (2005) applied the COPRAS method to evaluate contractors based on 26 criteria. Malinauskas and Kalibatas (2005) analyzed the manner of selecting an optimal building technological project in a few examples referring to the COPRAS method. Zavadskas et al. (2007) developed and implemented a methodology for multi-attribute assessing of multi-alternative decisions in road construction. Following a rough overview of multi-attribute decision support for assessing road design alternatives, the COPRAS approach was chosen. Banaitiene et al. (2008) considered the application of a methodology for the multivariate design and multiple criteria analysis of the life cycle of a building based on COPRAS. Kanapeckiene et al. (2011) used the COPRAS method for assessing the market value in the analysis of construction and retrofit projects. Medineckiene and Björk (2011) used COPRAS for preferences regarding renovation measures. Kildiene et al. (2011) used the entropy and COPRAS method for a comparative analysis of capabilities owned by European country management within the construction sector at the time of crisis. Chatterjee et al. (2011) employed the COPRAS method for selecting materials.

The inherent nature of uncertainty regarding the attribute value and their weights persuaded researchers to extend the COPRAS method under this condition. Zavadskas et al. (2008) developed and applied the COPRAS-G method dealing with the problem of matching managers to construction projects. Zavadskas et al. (2009), in terms of an assertion about the uncertainty of quantitative and qualitative assessment, used the methodology of grey relations for defining the utility of an alternative and proposed the application of the COPRAS-G method. Bindu Madhuri et al. (2010) put forward a multi attribute model for comparing the use of different websites and offered the application of the COPRAS-G method. Rezaeiniya et al. (2012) used ANP and COPRAS-G methods for greenhouse locating. Hashemkhani Zolfani et al. (2012) suggested a hybrid AHP and COPRAS-G method for selecting a quality control manager. Hashemkhani Zolfani et al. (2011) used AHP and COPRAS-G methods for finding the locations of forest roads. Yazdani et al. (2011) applied fuzzy COPRAS for the risk analysis of critical infrastructure. Maity et al. (2012) employed COPRAS-G for selecting materials. Fouladgar et al. (2012a) put forward a fuzzy MADM method based on COPRAS and AHP. Fouladgar et al. (2012b) used a new hybrid model for the evaluation of working strategies applying ANP and fuzzy COPRAS.

The aim of this paper is to extend the COPRAS method when the ratings of alternatives on attributes, attribute weights or both are expressed by the IVIFS. The paper is organized as follows: Section 1 reviews the original COPRAS method. Section 2 gives a brief review on the concept of IVIFSs and their operational rules. Section 3 introduces the extended COPRAS-IVIF method. Section 4 provides two applications of the introduced method. The final section consists of conclusions and proposals for future work. 


\section{The COPRAS method}

Multiple attribute decision aid provides several powerful and effective tools. Hwang and Yoon (1995), Vincke (1997), Figueira et al. (2005) and Zavadskas and Turskis (2011) presented a comprehensive overview of different MADM techniques. The COPRAS method introduced by Zavadskas et al. (1994) is an MADM technique that will be overviewed in this section. Suppose that we have a decision making problem consisting of $m$ alternatives that must be evaluated based on $n$ criteria and $x_{i j}$ is the value of the $i^{\text {th }}$ alternative in the $j^{\text {th }}$ criterion. The algorithm of the COPRAS method consists of the steps introduced below:

Step 1 . Select the available set of the most important attributes describing the alternatives.

Step 2. Prepare decision-making matrix $X$ :

$$
X=\left[\begin{array}{cccc}
x_{11} & x_{12} & \cdots & x_{1 n} \\
x_{21} & x_{22} & \cdots & x_{2 n} \\
\vdots & \vdots & \vdots & \vdots \\
x_{m 1} & x_{m 2} & \cdots & x_{m n}
\end{array}\right]
$$

Step 3. Determine the weights of attributes $w_{j}$.

Step 4. Normalize decision-making matrix $\bar{X}$. The normalized values of the matrix are calculated as

$$
\bar{x}_{i j}=x_{i j} / \sum_{i=1}^{m} x_{i j} ; i=1,2, \ldots, m ; j=1,2, \ldots, n .
$$

Step 5. Calculate weighted normalized decision-making matrix $\hat{X}$. Weighted normalized values $\hat{x}_{i j}$ are calculated as

$$
\hat{x}_{i j}=\bar{x}_{i j} \cdot w_{j} ; i=1,2, \ldots, m ; j=1,2, \ldots, n .
$$

In formula (3), $w_{j}$ is the weight of the $j^{\text {th }}$ attribute. Next, the weighted normalized decision-making matrix is obtained.

Step 6. Sum up attribute values where higher values are more preferable (maximization is a direction for optimization) and name $P_{i}$ for each alternative $i(i=1,2, \ldots, m)$ :

$$
P_{i}=\sum_{j=1}^{k} \hat{x}_{i j}
$$

In Eq. (4), $k$ is the number of attributes that must be maximized (it is assumed that in decision-making matrix columns, attributes having a maximum optimal direction are placed before a minimum optimal direction).

Step 7. Sum up attributes values where lower values are more preferable (minimization is a direction for optimization) and name $R_{i}$ for each alternative $i(i=1,2, \ldots, m)$ :

$$
R_{i}=\sum_{j=k+1}^{n} \hat{x}_{i j}
$$

Step 8. Determine the minimal value of $R_{i}$ :

$$
R_{\min }=\min _{i} R_{i} ; i=1,2, \ldots, m .
$$


26 S. H. Razavi Hajiagha et al. A complex proportional assessment method for group decision making...

Step 9. Calculate the relative weight of each alternative $Q_{i}$ :

$$
Q_{i}=P_{i}+\left(R_{\min } \sum_{i=1}^{m} R_{i}\right) /\left(R_{i} \sum_{i=1}^{m} R_{\min } / R_{i}\right) .
$$

Eq. (7) can be written as follows:

$$
Q_{i}=P_{i}+\left(\sum_{i=1}^{m} R_{i}\right) /\left(R_{i} \sum_{i=1}^{m} 1 / R_{i}\right)
$$

Step 10. Determine optimality criterion $K$ :

$$
K=\max _{i} Q_{i} ; i=1,2, \ldots, m .
$$

Step 11. Determine the priority of the projects. Greater weight $Q_{i}$ for alternative $i$ shows a higher priority (rank) of the alternative. In case of $Q_{\max }$, the satisfaction degree is the highest.

Step 12. Calculate the utility degree of each alternative:

$$
N_{i}=\left(Q_{i} / Q_{\max }\right) 100 \%
$$

where $Q_{i}$ and $Q_{\max }$ - the weights of the projects obtained from Eq. (8).

\section{Interval valued intuitionistic fuzzy sets}

Atanassov (1986) introduced the notion of intuitionistic fuzzy sets in the following way.

Definition 1. Let set $E$ be fixed. Intuitionistic fuzzy set $A$ in $E$ is defined as an object of the following form:

$$
A=\left\{\left\langle x, \mu_{A}(x), v_{A}(x)\right\rangle \mid x \in E\right\} .
$$

Where functions

$$
\mu_{A}: E \rightarrow[0,1]
$$

and

$$
v_{A}: E \rightarrow[0,1]
$$

define the degrees of the membership and non-membership of element $x \in E$, and for every $x \in E$

$$
0 \leq \mu_{A}(x)+v_{A}(x) \leq 1 .
$$

Atanassov and Gargov (1989) generalized the IFS to interval valued intuitionistic fuzzy sets as follows.

Definition 2. Let $D[0,1]$ be a set of all closed subintervals of interval $[0,1]$. Let $X$ be a given non-empty set. The IVIFS in $X$ is an expression given by $\tilde{A}=\left\{\left\langle x, \mu_{\tilde{A}}(x), v_{\tilde{A}}(x)\right\rangle \mid x \in X\right\}$ where $\mu_{\tilde{A}}: X \rightarrow D[0,1], v_{\tilde{A}}: X \rightarrow D[0,1]$ with condition $0<\sup _{x} \mu_{\tilde{A}}(x)+\sup _{x} v_{\tilde{A}}(x) \leq 1$.

Intervals $\mu_{\tilde{A}}(x)$ and $v_{\tilde{A}}(x)$ denote the degrees of the membership and non-membership of element $x$ in set $A$. Thus, for each $x \in X, \mu_{\tilde{A}}(x)$ and $v_{\tilde{A}}(x)$ are closed intervals the lower and upper end points of which are denoted $\mu_{A L}(x), \mu_{A U}(x), v_{A L}(x)$ and $v_{A U}(x)$. 
IVIFS $A$ is denoted by

$$
A=\left\{\left\langle x,\left[\mu_{A L}(x), \mu_{A U}(x)\right],\left[v_{A L}(x), v_{A U}(x)\right]\right\rangle \mid x \in X\right\},
$$

where $0<\mu_{A U}(x)+v_{A U}(x) \leq 1, \mu_{A L}(x), v_{A L}(x) \geq 0$. For convenience, the value of the IVIFS is denoted by $\tilde{A}=([a, b],[c, d])$ and called an interval valued intuitionistic fuzzy number (IVIFN).

Definition 3. Let $\tilde{A}_{1}=\left(\left[a_{1}, b_{1}\right],\left[c_{1}, d_{1}\right]\right)$ and $\tilde{A}_{2}=\left(\left[a_{2}, b_{2}\right],\left[c_{2}, d_{2}\right]\right)$ be any two IVIFNs. Then, their operational laws are defined as follows (Xu 2007):

$$
\begin{gathered}
\tilde{A}_{1}+\tilde{A}_{2}=\left(\left[a_{1}+a_{2}-a_{1} a_{2}, b_{1}+b_{2}-b_{1} b_{2}\right],\left[c_{1} c_{2}, d_{1} d_{2}\right]\right) ; \\
\tilde{A}_{1} \cdot \tilde{A}_{2}=\left(\left[a_{1} a_{2}, b_{1} b_{2}\right],\left[c_{1}+c_{2}-c_{1} c_{2}, d_{1}+d_{2}-d_{1} d_{2}\right]\right) ; \\
\lambda \tilde{A}_{1}=\left(\left[1-\left(1-a_{1}\right)^{\lambda}, 1-\left(1-b_{1}\right)^{\lambda}\right],\left[c_{1}^{\lambda}, d_{1}^{\lambda}\right]\right), \lambda \geq 0 .
\end{gathered}
$$

Definition 4. Let $\tilde{A}=([a, b],[c, d])$ be an IVIFN. Then,

$$
s(\tilde{A})=\frac{1}{2}(a-c+b-d)
$$

is called the score function of $\tilde{A}$, where $s(\tilde{A}) \in[-1,1]$ and

$$
h(\tilde{A})=\frac{1}{2}(a+c+b+d)
$$

is called the accuracy function of $A$, where $h(\tilde{A}) \in[0,1]$ (Xu 2007).

Definition 5. Let $\tilde{A}_{1}$ and $\tilde{A}_{2}$ be any two IVIFNs. Therefore,

1. If $s\left(\tilde{A}_{1}\right)<s\left(\tilde{A}_{2}\right)$, then $\tilde{A}_{1}$ is smaller than $\tilde{A}_{2}, \tilde{A}_{1}<\tilde{A}_{2}$.

2. If $s\left(\tilde{A}_{1}\right)=s\left(\tilde{A}_{2}\right)$, then

2.1. If $h\left(\tilde{A}_{1}\right)=h\left(\tilde{A}_{2}\right)$, then $\tilde{A}_{1}=\tilde{A}_{2}$.

2.2. If $h\left(\tilde{A}_{1}\right)<h\left(\tilde{A}_{2}\right)$, then $\tilde{A}_{1}$ is smaller than $\tilde{A}_{2}, \tilde{A}_{1}<\tilde{A}_{2}(\mathrm{Xu} 2007)$.

Definition 6. Let $\tilde{A}_{j}=\left(\left[a_{j}, b_{j}\right],\left[c_{j}, d_{j}\right]\right), j=1,2, \ldots, n$ be a collection of IVIFNs. Then, the generalized interval intuitionistic fuzzy weighted average $\operatorname{GIIFW}_{w}\left(\tilde{A}_{1}, \tilde{A}_{2}, \ldots, \tilde{A}_{n}\right)$ is defined as follows:

$$
\operatorname{GIIFWA}_{w}\left(A_{1}, A_{2}, \ldots, A_{n}\right)=\left(w_{1} \tilde{A}_{1}^{\lambda}+w_{2} \tilde{A}_{2}^{\lambda}+\ldots+w_{n} \tilde{A}_{n}^{\lambda}\right)^{1 / \lambda}
$$

where $\lambda>0$, and $w=\left(w_{1}, w_{2}, \ldots, w_{n}\right)^{T}$ is weight vector with $w_{j} \geq 0, j=1,2, \ldots, n$, and $\sum_{j=1}^{n} w_{j}=1$. 
It can be shown that GIIFWA is also an IVIFN and can be calculated as follows (Zhao et al. 2010):

$$
\begin{aligned}
& \operatorname{GIIFWA}_{w}\left(\tilde{A}_{1}, \tilde{A}_{2}, \ldots, \tilde{A}_{n}\right)=\left(\left[\left(1-\prod_{j=1}^{n}\left(1-a_{j}^{\lambda}\right)^{w_{j}}\right)^{1 / \lambda},\left(1-\prod_{j=1}^{n}\left(1-b_{j}^{\lambda}\right)^{w_{j}}\right)^{1 / \lambda}\right],\right. \\
& \left.\left[1-\left(1-\prod_{j=1}^{n}\left(1-\left(1-c_{j}\right)^{\lambda}\right)^{w_{j}}\right)^{1 / \lambda}, 1-\left(1-\prod_{j=1}^{n}\left(1-\left(1-d_{j}\right)^{\lambda}\right)^{w_{j}}\right)^{1 / \lambda}\right]\right),
\end{aligned}
$$

if $\lambda=1$, then GIIFWA is turned into interval intuitionistic fuzzy weighted average (IIFWA).

\section{COPRAS with IVIF information}

In this section, the COPRAS method is extended under the condition that information on the decision making problem has appeared in the form of the IVIFS.

Suppose a decision making problem, as defined in Section 3, containing $m$ alternatives $A_{i}, i=1,2, \ldots, m$ and $n$ criteria $C_{j}, j=1,2, \ldots, n$ for evaluating those alternatives. Assume that a group of $K$ experts participate in the decision making process. Also, the ratings of alternatives on attributes and/ or attribute weights are not determined exactly and are expressed by IVIFNs. The process of group decision making applying the COPRAS-IVIF method is developed following the below steps.

Step 1. Determine the importance of decision makers. While the decision is made by a group of decision makers, first, the importance or share of each decision maker considering the final decision is determined. Suppose that $\lambda=\left(\lambda_{1}, \lambda_{2}, \ldots, \lambda_{K}\right)$ is a vector indicating the importance of decision makers, where $\lambda_{k} \geq 0, k=1,2, \ldots, K$ is the importance of the $k^{\text {th }}$ decision maker and $\sum_{k=1}^{K} \lambda_{k}=1$. Note that if decision makers are of similar importance, $\lambda_{1}=\lambda_{2}=\ldots=\lambda_{K}=1 / K$.

Step 2. Individual evaluations. On this step, each expert expresses his or her evaluations regarding the ratings of alternatives on attributes and attribute weights. Suppose that $\tilde{x}_{i j}^{k}, i=1,2, \ldots, m ; j=1,2, \ldots, n$ is the $k^{\text {th }}$ expert's evaluation of alternative $A_{i}$ rating on criterion $j$ stated by IVIFN $\tilde{x}_{i j}^{k}=\left(\left[\mu_{L i j}^{k}, \mu_{U i j}^{k}\right],\left[v_{L i j}^{k}, v_{U i j}^{k}\right]\right)$. Then, the decision matrix of expert $k$ is constructed as follows:

$$
\tilde{X}^{k}=\left[\begin{array}{cccc}
\tilde{x}_{11}^{k} & \tilde{x}_{12}^{k} & \ldots & \tilde{x}_{1 n}^{k} \\
\tilde{x}_{21}^{k} & \tilde{x}_{22}^{k} & \ldots & \tilde{x}_{2 n}^{k} \\
\vdots & \vdots & \vdots & \vdots \\
\tilde{x}_{m 1}^{k} & \tilde{x}_{m 2}^{k} & \ldots & \tilde{x}_{m n}^{k}
\end{array}\right] .
$$

Synchronously, expert $k$ expresses his or her judgments regarding the weights of criteria. Suppose that $\tilde{w}_{j}^{k}=\left(\left[\mu_{L j}^{k}, \mu_{U j}^{k}\right],\left[v_{L j}^{k}, v_{U j}^{k}\right]\right)$ is the $k^{\text {th }}$ expert's judgment on the importance of the $j^{\text {th }}$ criterion. 
Step 3. Determine the weights of criteria. On this step, the aggregated weights of criteria are determined calculating the IIFWA operator, Eq. (22), of criterion weights defined by decision makers. If $\tilde{w}_{j}^{k}, k=1,2, \ldots, K$ are the weights of criterion $j$ expressed by decision makers, then, the aggregated weight of criterion $j, \tilde{w}_{j}=\left(\left[\mu_{L j}, \mu_{U j}\right],\left[v_{L j}, v_{U j}\right]\right)$, will be computed as follows:

$$
\begin{aligned}
& w_{j}=I I F W A_{\lambda}\left(\tilde{w}_{j}^{1}, \tilde{w}_{j}^{2}, \ldots, \tilde{w}_{j}^{K}\right)=\left(\left[\left(1-\prod_{k=1}^{K}\left(1-\mu_{L j}^{k}\right)^{\lambda_{k}}\right),\left(1-\prod_{k=1}^{K}\left(1-\mu_{U j}^{k}\right)^{\lambda_{k}}\right)\right],\right. \\
& \left.\left[\prod_{k=1}^{K}\left(v_{L j}^{k}\right)^{\lambda_{k}}, \prod_{k=1}^{K}\left(v_{U j}^{k}\right)^{\lambda_{k}}\right]\right) .
\end{aligned}
$$

Step 4. Construct the aggregated decision matrix applying IIFWA operators to the elements of individual decision matrices. The aggregated decision matrix will be as follows:

$$
\tilde{X}^{k}=\left[\begin{array}{cccc}
\tilde{x}_{11} & \tilde{x}_{12} & \ldots & \tilde{x}_{1 n} \\
\tilde{x}_{21} & \tilde{x}_{22} & \ldots & \tilde{x}_{2 n} \\
\vdots & \vdots & \vdots & \vdots \\
\tilde{x}_{m 1} & \tilde{x}_{m 2} & \ldots & \tilde{x}_{m n}
\end{array}\right],
$$

where element $\tilde{x}_{i j}=\left(\left[\mu_{L i j}, \mu_{U i j}\right],\left[v_{L i j}, v_{U i j}\right]\right)$ means the rating of alternative $A_{i}$ on criterion $j$ and is calculated as follows:

$$
\begin{aligned}
& \tilde{x}_{i j}=I I F W A_{\lambda}\left(x_{i j}^{1}, x_{i j}^{2}, \ldots, x_{i j}^{K}\right)=\left(\left[\left(1-\prod_{k=1}^{K}\left(1-\mu_{L i j}^{k}\right)^{\lambda_{k}}\right),\left(1-\prod_{k=1}^{K}\left(1-\mu_{U i j}^{k}\right)^{\lambda_{k}}\right)\right],\right. \\
& \left.\left[\prod_{k=1}^{K}\left(v_{L i j}^{k}\right)^{\lambda_{k}}, \prod_{k=1}^{K}\left(v_{U i j}^{k}\right)^{\lambda_{k}}\right]\right) .
\end{aligned}
$$

Step 5. Calculate the weighted matrix. According to Eq. (3), the weighted matrix is calculated as $\hat{\tilde{X}}=\left[\hat{\tilde{x}}_{i j}\right], i=1,2, \ldots, n ; j=1,2, \ldots, m$, where $\hat{\tilde{x}}_{i j}=\tilde{x}_{i j} \cdot \tilde{w}_{j}$. Following Eq. (17),

$$
\hat{\tilde{x}}_{i j}=\left(\left[\mu_{L i j} \mu_{L j}, \mu_{U i j} \mu_{U j}\right],\left[v_{L i j}+v_{L j}-v_{L i j} v_{L j}, v_{u i j}+v_{u j}-v_{U i j} v_{U j}\right]\right) \text {. }
$$

Step 6. Sum the values of criteria for benefit. Let $J=\{1,2, \ldots, l\}$ be a set of criteria the higher values of which are better. Then, calculate the following index for each alternative:

$$
\tilde{P}_{i}=\sum_{j \in J} \hat{\tilde{x}}_{i j}
$$

where the sum is done based on Eq. (16).

Step 7. Sum the values of cost criteria. Let $J^{\prime}=\{l+1, l+2, \ldots, n\}$ be a set of criteria the lower values of which are better. Then, calculate the following index for each alternative.

$$
\tilde{R}_{i}=\sum_{j \in J^{\prime}} \hat{\tilde{x}}_{i j} \cdot
$$


30 S. H. Razavi Hajiagha et al. A complex proportional assessment method for group decision making...

Step 8. Determine the minimal value of $\tilde{R}_{i}$ referring to Definition 5.

Step 9. Calculate the relative weight of each alternative $\left(Q_{i}\right)$. Let $s\left(\tilde{R}_{i}\right)$ and $s\left(\tilde{P}_{i}\right)$ be the scores of $\tilde{R}_{i}$ and $\tilde{P}_{i}$ respectively.

Eq. (30) can be written as follows:

$$
Q_{i}=s\left(\tilde{P}_{i}\right)+\frac{s\left(\tilde{R}_{\min }\right) \sum_{i=1}^{m} s\left(\tilde{R}_{i}\right)}{s\left(\tilde{R}_{i}\right) \sum_{i=1}^{m} \frac{s\left(\tilde{R}_{\min }\right)}{s\left(\tilde{R}_{i}\right)}} .
$$

$$
Q_{i}=s\left(\tilde{P}_{i}\right)+\frac{\sum_{i=1}^{m} s\left(\tilde{R}_{i}\right)}{s\left(\tilde{R}_{i}\right) \sum_{i=1}^{m} \frac{1}{s\left(\tilde{R}_{i}\right)}} .
$$

Step 10. Determine optimality criterion $K$.

$$
K=\max _{i} Q_{i} ; i=1,2, \ldots, m .
$$

Step 11. Determine the priority of alternatives. The greater weight $Q_{i}$ for alternative $i$ shows, the higher is the priority (rank) of the alternative. The utility degree of each alternative is defined as follows:

$$
N_{i}=\left(Q_{i} / Q_{\max }\right) 100 \%
$$

\section{Numerical examples}

This section analyzes some application examples of MCDM problems previously solved with the help of different methods.

Example 1. Wang et al. (2009) examined a decision problem consisting of the evaluation of four potential investment alternatives $A=\left\{A_{1}, A_{2}, A_{3}, A_{4}\right\}$ based on four attributes: risk $\left(C_{1}\right)$, growth $\left(C_{2}\right)$, socio-political issues $\left(C_{3}\right)$ and environment impacts $\left(C_{4}\right)$. The fund manager provided each alternative on each attribute as an IVIFN. The provided decision matrix is as follows:

$$
\begin{aligned}
& \begin{array}{llll}
C_{1} & C_{2} & C_{3} & C_{4}
\end{array}
\end{aligned}
$$

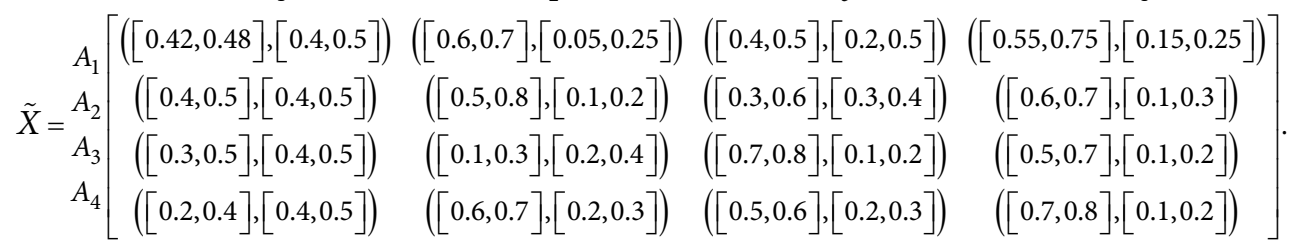

Also, the fund manager determines attribute weights as $w_{1}=0.13, w_{2}=0.17, w_{3}=0.39$ and $w_{4}=0.31$. While there is only one decision maker, COPRAS-IVIF is started from Step 5 . 
Since attribute weights are expressed as crisp numbers, the values of $\hat{\tilde{x}}_{i j}$ are computed based on Eq. (18) as follows:

$$
\hat{\tilde{x}}_{i j}=\left(\left[1-\left(1-\mu_{L i j}\right)^{w_{j}}, 1-\left(1-\mu_{U i j}\right)^{w_{j}}\right],\left[v_{L i j}^{w_{j}}, v_{U i j}^{w_{j}}\right]\right) .
$$

Therefore, the weighted matrix is provided in the following way:

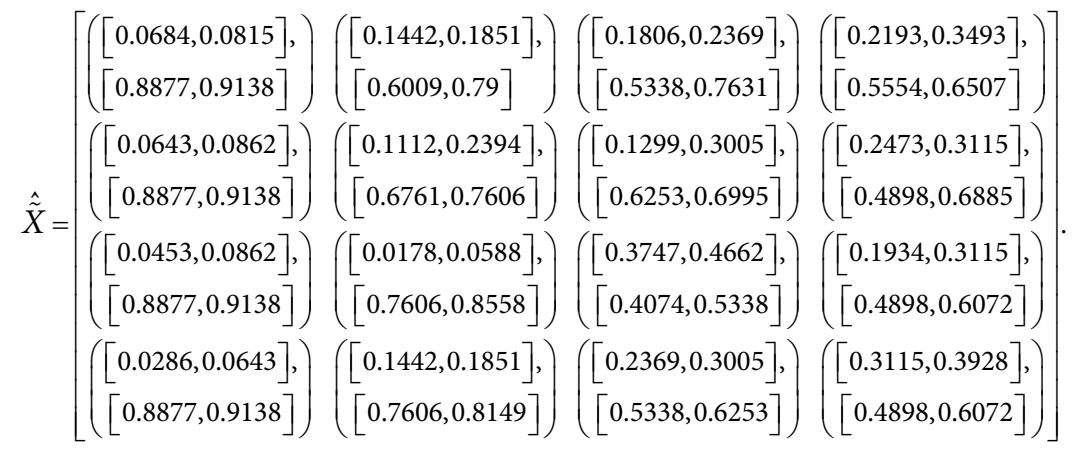

Table 1 shows the values of $\tilde{P}_{i}, \tilde{R}_{i}$ and $\tilde{Q}_{i}$ for alternatives while $C_{1}$ is considered as the cost criterion and other criteria as benefit.

Table 1. The values of $\tilde{P}_{i}, \tilde{R}_{i}$ and $\tilde{Q}_{i}$ taking into account alternatives

\begin{tabular}{ccccc}
\hline Alternative & $\tilde{P}_{i}$ & $\tilde{R}_{i}$ & $\tilde{Q}_{i}$ & Rank \\
\hline$A_{1}$ & $([0.4526,0.5954],[0.1782,0.3923])$ & $([0.0684,0.0815],[0.8877,0.9138])$ & -0.60574 & 3 \\
\hline$A_{2}$ & $([0.4178,0.6337],[0.2071,0.3662])$ & $([0.0643,0.0862],[0.8877,0.9138])$ & -0.60567 & 4 \\
\hline$A_{3}$ & $([0.5046,0.6541],[0.1518,0.2774])$ & $([0.0453,0.0862],[0.8877,0.9138])$ & -0.47044 & 2 \\
\hline$A_{4}$ & $([0.5504,0.6539],[0.1989,0.3094])$ & $([0.0286,0.0643],[0.8877,0.9138])$ & -0.46831 & 1 \\
\hline
\end{tabular}

The obtained ranking of the COPRAS-IVIF method, $A_{4} \succ A_{3} \succ A_{1} \succ A_{2}$, is completely consistent with the results provided by Wang et al. (2009).

Note that the membership function can be considered as the satisfaction degree and non-membership degree, as a decision maker's dissatisfaction, regarding the level of a given alternative, meets the requirements of a certain criterion. In fact, decision makers can make their evaluations in the form of a satisfaction and dissatisfaction degree as IFSs. Next, these IFSs can be turned into equivalent IVIFSs employing the method proposed by Bustince and Burillo (1995).

Example 2. Assume that a manufacturing company wants to outsource its annual maintenance operation. The company received four proposals from external maintenance service providers (MSP). A team consisting of three members is formed to choose the best MSP. The team members are of equal importance, i.e. $\lambda=(1 / 3,1 / 3,1 / 3)$. Also, four criteria, including the proposed price $\left(C_{1}\right)$, maintenance duration $\left(C_{2}\right)$, reputation $\left(C_{3}\right)$ and workers speciality $\left(C_{4}\right)$ are considered to appraise these candidates. The decision making process involves the following steps. 
32 S. H. Razavi Hajiagha et al. A complex proportional assessment method for group decision making...

Steps 1-2. Each decision maker performs his/her evaluations with regard to the rating of alternatives on attributes. Decision makers have made evaluations in linguistic terms later turned to IVIFNs. Boran et al. (2009) developed a scale of performing evaluations based on the IFS. In this case, with reference to the theorem proposed by Bustince and Burillo's (1995), the scale is transformed into the equivalent IVIFS scale.

Based on the IVIFN scale presented in Table 2, decision makers perform their evaluations of alternatives. Individual decision matrices are presented in Table 3.

Table 2 . The IVIFN scale to rate alternatives to criteria

\begin{tabular}{ll}
\hline \multicolumn{1}{c}{ Linguistic term } & \multicolumn{1}{c}{ IVIFNs } \\
\hline Extremely good (EG)/ extremely high $(\mathrm{EH})$ & $([1,1],[0,0])$ \\
Very very good $(\mathrm{VVG}) /$ very very high $(\mathrm{VVH})$ & $([0.9,0.9],[0.1,0.1])$ \\
Very good $(\mathrm{VG}) /$ very high $(\mathrm{VH})$ & $([0.7333,0.825],[0,0.125])$ \\
Good $(\mathrm{G}) /$ high $(\mathrm{H})$ & $([0.6333,0.725],[0.1,0.225])$ \\
Medium good $(\mathrm{MG}) /$ medium high $(\mathrm{MH})$ & $([0.5333,0.625],[0.2,0.325])$ \\
Fair $(\mathrm{F}) /$ medium $(\mathrm{M})$ & $([0.4333,0.525],[0.3,0.425])$ \\
Medium bad $(\mathrm{MB}) /$ medium low $(\mathrm{ML})$ & $([0.3333,0.425],[0.4,0.525])$ \\
Bad $(\mathrm{B}) /$ low $(\mathrm{L})$ & $([0.15,0.2875],[0.45,0.6375])$ \\
Very bad $(\mathrm{VB}) /$ very low $(\mathrm{VL})$ & $([0,0.1375],[0.6,0.7875])$ \\
Very very bad $(\mathrm{VVL}) /$ very very low $(\mathrm{VVL})$ & $([0.1,0.1],[0.9,0.9])$ \\
\hline
\end{tabular}

Table 3. Individual decision matrices

\begin{tabular}{ccccc}
\hline DM1 & $C_{1}$ & $C_{2}$ & $C_{3}$ & $C_{4}$ \\
\hline$A_{1}$ & $\mathrm{MH}$ & $\mathrm{M}$ & $\mathrm{L}$ & $\mathrm{H}$ \\
\hline$A_{2}$ & $\mathrm{H}$ & $\mathrm{M}$ & $\mathrm{H}$ & $\mathrm{MH}$ \\
\hline$A_{3}$ & $\mathrm{M}$ & $\mathrm{H}$ & $\mathrm{MH}$ & $\mathrm{VH}$ \\
\hline$A_{4}$ & $\mathrm{M}$ & $\mathrm{MH}$ & $\mathrm{M}$ & $\mathrm{MH}$ \\
\hline $\mathrm{DM} 2$ & $C_{1}$ & $\mathrm{C}_{2}$ & $\mathrm{C}_{3}$ & $C_{4}$ \\
\hline$A_{1}$ & $\mathrm{M}$ & $\mathrm{ML}$ & $\mathrm{MH}$ & $\mathrm{H}$ \\
\hline$A_{2}$ & $\mathrm{MH}$ & $\mathrm{H}$ & $\mathrm{H}$ & $\mathrm{H}$ \\
\hline$A_{3}$ & $\mathrm{MH}$ & $\mathrm{VH}$ & $\mathrm{H}$ & $\mathrm{MH}$ \\
\hline$A_{4}$ & $\mathrm{M}$ & $\mathrm{M}$ & $\mathrm{ML}$ & $\mathrm{ML}$ \\
\hline $\mathrm{DM} 3$ & $\mathrm{C}_{1}$ & $\mathrm{C}_{2}$ & $\mathrm{C}_{3}$ & $\mathrm{C}_{4}$ \\
\hline$A_{1}$ & $\mathrm{H}$ & $\mathrm{MH}$ & $\mathrm{ML}$ & $\mathrm{VH}$ \\
\hline$A_{2}$ & $\mathrm{VH}$ & $\mathrm{M}$ & $\mathrm{H}$ & $\mathrm{H}$ \\
\hline$A_{3}$ & $\mathrm{H}$ & $\mathrm{MH}$ & $\mathrm{MH}$ & $\mathrm{MH}$ \\
\hline$A_{4}$ & $\mathrm{MH}$ & $\mathrm{M}$ & $\mathrm{M}$ & $\mathrm{M}$ \\
\hline & & & &
\end{tabular}

Step 3. Decision makers also express their judgments with regard to the importance of criteria for evaluating alternatives. Boran et al. (2009) also presented an intuitionistic fuzzy scale of judgments that, in our case, are transformed into the IVIF scale based on the theorem developed by Bustince and Burillo (1995). Table 4 shows the IVIF scale to evaluate the weights of criteria.

Table 5 shows the preference of decision makers for the weights of criteria. 
Table 4. Linguistic terms for rating the importance of criteria

\begin{tabular}{ll}
\hline \multicolumn{1}{c}{ Linguistic term } & \multicolumn{1}{c}{ IVIFNs } \\
\hline Very important $(\mathrm{VI})$ & $([0.9,0.9],[0.1,0.1])$ \\
Important $(\mathrm{I})$ & $([0.4,0.7625],[0,0.2115])$ \\
Medium $(\mathrm{M})$ & $([0.15,0.5125],[0.25,0.4625])$ \\
Unimportant $(\mathrm{U})$ & $([0,0.3625],[0.4,0.6125])$ \\
Very unimportant $(\mathrm{VU})$ & $([0.1,0.1],[0.9,0.9])$ \\
\hline
\end{tabular}

Table 5. Individual decision matrices

\begin{tabular}{ccccc}
\hline & $C_{1}$ & $C_{2}$ & $C_{3}$ & $C_{4}$ \\
\hline DM1 & $\mathrm{M}$ & $\mathrm{M}$ & $\mathrm{I}$ & $\mathrm{I}$ \\
\hline DM2 & $\mathrm{I}$ & $\mathrm{I}$ & $\mathrm{M}$ & $\mathrm{I}$ \\
\hline DM3 & $\mathrm{I}$ & $\mathrm{M}$ & $\mathrm{U}$ & $\mathrm{I}$ \\
\hline
\end{tabular}

The aggregated weights of criteria based on Eq. (24) and importance vector $\lambda$ found by decision makers are determined as follows:

$$
\begin{array}{cc}
\tilde{w}_{1}=([0.3261,0.6982],[0,0.2745]) & \tilde{w}_{2}=([0.2432,0.6164],[0,0.3563]) \\
\tilde{w}_{3}=([0.2010,0.5805],[0,0.3913]) & \tilde{w}_{4}=([0.4,0.7625],[0,0.2115])
\end{array}
$$

Step 4. The aggregated decision matrix is constructed following Eq. (26) and importance vector $\lambda$ established by decision makers as follows:

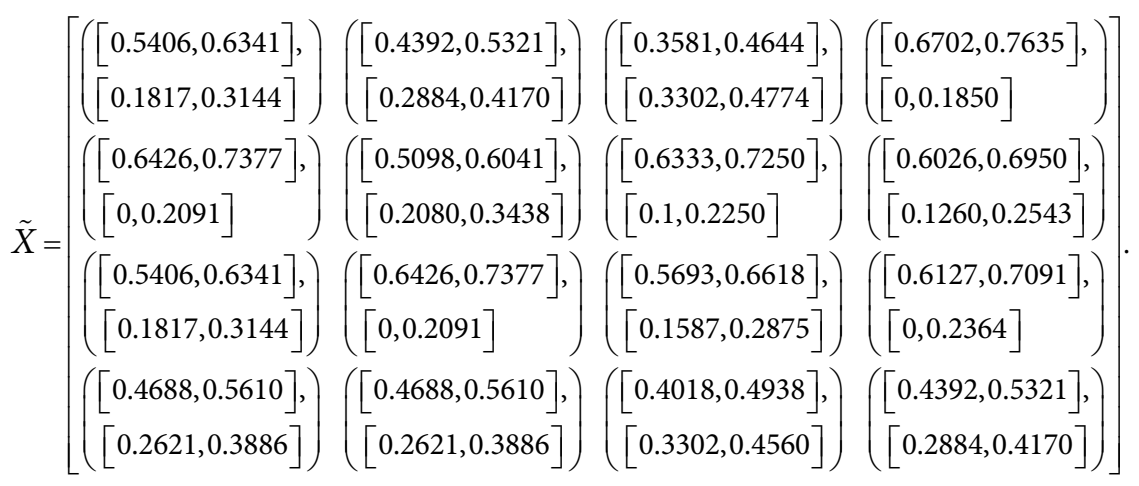

Step 5. Based on Eq. (27), the weighted matrix is formed as follows.

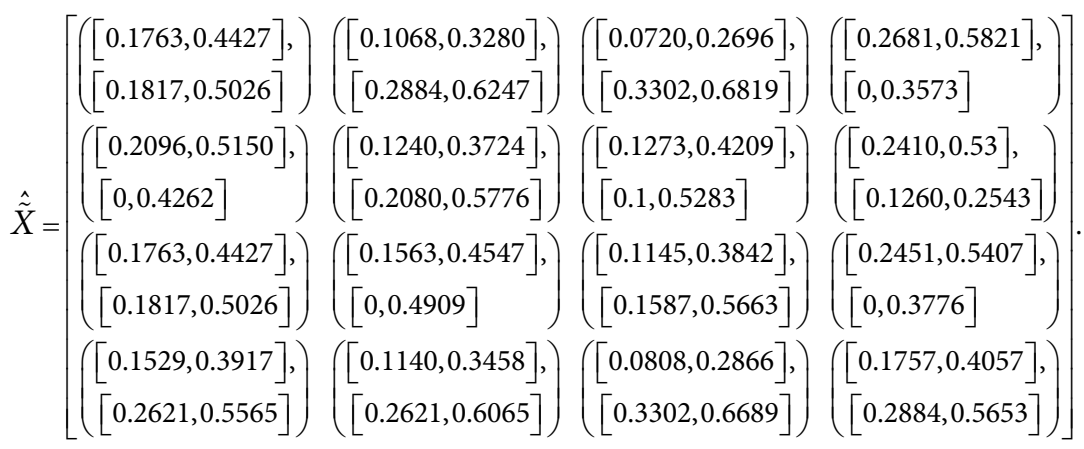


34 S. H. Razavi Hajiagha et al. A complex proportional assessment method for group decision making...

Steps 6-11. Since $C_{1}$ and $C_{2}$ are cost criteria and $C_{3}$ and $C_{4}$ are criteria for benefit, the computed values of $\tilde{P}_{i}, \tilde{R}_{i}$ and $\tilde{Q}_{i}$ for each alternative are shown in Table 6 .

Table 6. The values of $\tilde{P}_{i}, \tilde{R}_{i}$ and $\tilde{Q}_{i}$ for alternatives

\begin{tabular}{cllll}
\hline Alternative & \multicolumn{1}{c}{$\tilde{P}_{i}$} & \multicolumn{1}{c}{$\tilde{R}_{i}$} & $\tilde{Q}_{i}$ & Rank \\
\hline$A_{1}$ & $([0.3208,0.6948],[0,0.2437])$ & $([0.2643,0.6255],[0.0524,0.3140])$ & 0.7343 & 1 \\
\hline$A_{2}$ & $([0.3377,0.7278],[0.0126,0.1344])$ & $([0.3076,0.6956],[0,0.2462])$ & 0.7001 & 2 \\
\hline$A_{3}$ & $([0.3315,0.7172],[0,0.2138])$ & $([0.3050,0.6961],[0,0.2467])$ & 0.6590 & 3 \\
\hline$A_{4}$ & $([0.2423,0.5761],[0.0952,0.3781])$ & $([0.2495,0.6020],[0.0687,0.3375])$ & 0.5818 & 4 \\
\hline
\end{tabular}

Therefore, the final ranking is $A_{1} \succ A_{2} \succ A_{3} \succ A_{4}$. The example shows the process of decision making applying the proposed COPRAS-IVIF method from the beginning to the end.

\section{Conclusions}

Decision making solving practical problems is a often group activity that requires the judgments of decision makers about the importance of a set of criteria and alternatives. These evaluations are always performed with ambiguity based on ill-defined information. Ignoring this ambiguity and uncertainty in decision making may mislead the decision process to an unfair decision. To avoid this problem, scholars developed some procedures to handle uncertainty in decision making. Interval valued intuitionistic fuzzy sets, as a generalized form of fuzzy sets, can be considered as a powerful mean to convey uncertainty in a good manner in decision making. In this paper, the COPRAS method is extended for group decision making in an interval valued intuitionistic fuzzy environment. IVIF data provide a more realistic picture from uncertain aspects of real world problems, and therefore an algorithmic scheme for making decisions employing the above discussed method has been proposed. A combination of IVIFN arithmetic and aggregation operators is used for developing COPRAS-IVIF. Also, some scales are promoted to perform evaluations based on linguistic terms and IVIFNs. The application of the proposed method is examined in two numerical examples. The suggested method can be applied dealing with various selection and ranking problems in different fields as a common uncertain decision analysis method.

\section{References}

Andruškevicius, A. 2005. Evaluation of contractors by using COPRAS - the multiple criteria method, Technological and Economic Development of Economy 11(3):158-169.

Antucheviciene, J.; Zakarevičius, A.; Zavadskas, E. K. 2011. Measuring congruence of ranking results applying particular MCDM methods, Informatica 22(3): 319-338.

Atanassov, K. 1986. Intuitionistic fuzzy sets, Fuzzy Sets and Systems 20(1): 87-96. http://dx.doi.org/10.1016/S0165-0114(86)80034-3

Atanassov, K.; Gargov, G. 1989. Interval valued intuitionistic fuzzy sets, Fuzzy Sets and Systems 31(3): 343-349. http://dx.doi.org/10.1016/0165-0114(89)90205-4 
Banaitiene, N.; Banaitis, A.; Kaklauskas, A.; Zavadskas, E. K. 2008. Evaluating the life cycle of a building: a multivariant and multiple criteria approach, Omega 36(3):429-441.

http://dx.doi.org/10.1016/j.omega.2005.10.010

Bindu Madhuri, C. H.; Chandulal, J. A.; Padmaja, M. 2010. Selection of best web site by applying COPRAS-G method, International Journal of Computer Science and Information Technologies $1(2): 138-146$.

Boran, F. E.; Genc, S.; Kurt, M.; Akay, D. 2009. A multi-criteria intuitionistic fuzzy group decision making for supplier selection with TOPSIS method, Expert Systems with Applications 36(8): 11363-11368. http://dx.doi.org/10.1016/j.eswa.2009.03.039

Bragge, J.; Korhonen, P.; Wallenius, H.; Wallenius, J. 2012. Scholarly communities of research in multiple criteria decision making: a bibliometric research profiling study, International Journal of Information Technology \& Decision Making 11(2): 401-426. http://dx.doi.org/10.1142/S0219622012400081

Bustince, H.; Burillo, P. 1995. A theorem for construction interval-valued intuitionistic fuzzy sets from intuitionistic fuzzy sets, Notes on IFS 1(1): 5-16.

Chatterjee, P.; Athawale, V. M.; Chakraborty, S. 2011. Materials selection using complex proportional assessment and evaluation of mixed data methods, Materials and Design 32(2): 851-860. http://dx.doi.org/10.1016/j.matdes.2010.07.010

Chen, S. M.; Lee, L. W.; Liu, H. C.; Yang, S. W. 2012. Multiattribute decision making based on intervalvalued intuitionistic fuzzy values, Expert Systems with Applications 39(12): 10343-10351. http://dx.doi.org/10.1016/j.eswa.2012.01.027

Climaco, J. 1997. Multicriteria analysis. New York: Springer. http://dx.doi.org/10.1007/978-3-642-60667-0

Figueira, J.; Greco, S.; Ehrgott, M. 2005. Multiple criteria decision analysis: state of the art surveys. Springer, New York.

Fouladgar, M. M.; Yazdani-Chamzini, A.; Lashgari, A.; Zavadskas, E. K.; Turskis, Z. 2012a. Maintenance strategy selection using AHP and COPRAS under fuzzy environment, International Journal of Strategic Property Management 16(1): 85-104. http://dx.doi.org/10.3846/1648715X.2012.666657

Fouladgar, M. M.; Yazdani-Chamzini, A.; Zavadskas, E. K.; Moini, H. H. 2012b. A new hybrid model for evaluating the working strategies: case study of construction company, Technological and Economic Development of Economy 18(1): 164-188. http://dx.doi.org/10.3846/20294913.2012.667270

Gau, W. L.; Buehrer, D. J. 1993. Vague sets, IEEE Transactions on Systems, Man and Cybernetics 23(2): 610-614. http://dx.doi.org/10.1109/21.229476

Grattan-Guinness, I. 1976. Fuzzy membership mapped onto interval and many-valued quantities, Mathematical Logic Quarterly 22(1): 149-160. http://dx.doi.org/10.1002/malq.19760220120

Hashemkhani Zolfani, S.; Rezaeiniya, N.; Aghdaie, M. H.; Zavadskas, E. K. 2012. Quality control manager selection based on AHP-COPRAS-G methods: a case in Iran, Ekonomska istrazivanja - Economic Research 25(1): 88-104.

Hashemkhani Zolfani, S.; Rezaeiniya, N.; Zavadskas, E. K.; Turskis, Z. 2011. Forest roads locating based on AHP and COPRAS-G methods: an empirical study based on Iran, E\&M Ekonomie a Management 14(4): 6-21.

Hwang, C. L.; Yoon, K. P. 1995. Multiple attribute decision making: an introduction. Berlin: Springer-Verlag.

Kanapeckiene, L.; Kaklauskas, A.; Zavadskas, E. K.; Raslanas, S. 2011. Method and system for multiattribute market value assessment in analysis of construction and retrofit projects, Expert Systems with Applications 38(11): 14196-14207. http://dx.doi.org/10.1016/j.eswa.2011.04.232

Kildiene, S.; Kaklauskas, A.; Zavadskas, E. K. 2011. COPRAS based comparative analysis of the European country management capabilities within the construction sector in the time of crisis, Journal of Business Economics and Management 12(2): 417-434. http://dx.doi.org/10.3846/16111699.2011.575190 
36 S. H. Razavi Hajiagha et al. A complex proportional assessment method for group decision making...

Kou, G.; Lu, Y.; Peng, Y.; Shi, Y. 2012. Evaluation of classification algorithms using mcdm and rank correlation, International Journal of Information Technology \& Decision Making 1(1): 197-225. http://dx.doi.org/10.1142/S0219622012500095

Li, D. F. 2005. Multiattribute decision making models and methods using intuitionistic fuzzy sets, Journal of Computer and System Sciences 70(1): 73-85. http://dx.doi.org/10.1016/j.jcss.2004.06.002

Li, D. F. 2008. Extension of the LINMAP for multiattribute decision making under Atanassov's intuitionistic fuzzy environment, Fuzzy Optimization and Decision Making 7(1): 17-34. http://dx.doi.org/10.1007/s10700-007-9022-x

Li, D. F. 2010a. Multiattribute decision making method based on generalized OWA operators with intuitionisticfuzzy sets, Expert Systems with Applications 37(12): 8673-8678. http://dx.doi.org/10.1016/j.eswa.2010.06.062

Li, D. F. 2010b. Linear programming method for MADM with interval-valued intuitionistic fuzzy sets, Expert Systems with Applications 37(8): 5939-5945. http://dx.doi.org/10.1016/j.eswa.2010.02.011

Li, D. F.; Wang, Y. C.; Liu, S.; Shan, F. 2009. Fractional programming methodology for multi-attribute group decision-making using IFS, Applied Soft Computing 9(1): 219-225. http://dx.doi.org/10.1016/j.asoc.2008.04.006

Maity, S. R.; Chatterjee, P.; Chakraborty, S. 2012. Cutting tool material selection using grey complex proportional assessment method, Materials \& Design 36: 372-378. http://dx.doi.org/10.1016/j.matdes.2011.11.044

Malinauskas, P.; Kalibatas, D. 2005. The selection of rational constructional technology processes variants using COPRAS method, Technological and Economic Development of Economy 11(3): 197-205.

Medineckiene, M.; Björk, F. 2011. Owner preferences regarding renovation measures - the demonstration of using multi-criteria decision making, Journal of Civil Engineering and Management 17(2): 284-295.

Park, J. H.; Park, I. Y.; Kwun, Y. C.; Tan, X. 2011. Extension of the TOPSIS method for decision making problems under interval-valued intuitionistic fuzzy environment, Applied Mathematical Modelling 35(5): 2544-2556. http://dx.doi.org/10.1016/j.apm.2010.11.025

Rezaeiniya, N.; Hashemkhani Zolfani, S.; Zavadskas, E. K. 2012. Greenhouse locating based on ANP-COPRAS-G methods - an empirical study based on Iran, International Journal of Strategic Property Management 16(2): 188-200. http://dx.doi.org/10.3846/1648715X.2012.686459

Riabacke, A. 2006. Managerial decision making under risk and uncertainty, IAENG International Journal of Computer Science 32: 453-459.

Triantaphyllou, E. 2000. Multi-criteria decision making methods: a comparative study. London: Kluwer Academic.

Vahdani, B.; Mousavi, S. M.; Tavakkoli-Moghaddam, R.; Hashemi, H. 2012. A new design of the elimination and choice translating reality method for multi-criteria group decision-making in an intuitionistic fuzzy environment, Applied Mathematical Modelling 37(4): 1781-1799. http://dx.doi.org/10.1016/j.apm.2012.04.033

Verma, A. K.; Verma, R.; Mahanti, N. C. 2010. Facility location selection: an interval valued intuitionistic fuzzy topsis approach, Journal of Modern Mathematics and Statistics 4(2): 68-72. http://dx.doi.org/10.3923/jmmstat.2010.68.72

Vincke, P. 1997. Multicriteria decision-aid. John Wiley, Chichester.

Wang, Z.; Li, K. W.; Wang, W. 2009. An approach to multiattribute decision making with interval-valued intuitionistic fuzzy assessments and incomplete weights, Information Sciences 179(17): 3026-3040. http://dx.doi.org/10.1016/j.ins.2009.05.001

$\mathrm{Xu}, \mathrm{Z}$. S. 2007. Methods for aggregating interval-valued intuitionistic fuzzy information and their application to decision making, Control and Decision 22(2): 215-219. 
$\mathrm{Xu}, \mathrm{Z}$. 2012. Intuitionistic fuzzy multiattribute decision making: an interactive method, IEEE Transactions on Fuzzy Systems 20(3): 514-525. http://dx.doi.org/10.1109/TFUZZ.2011.2177466

Yazdani, M.; Alidoosti, A.; Zavadskas, E. K. 2011. Risk analysis of critical infrastructures using fuzzy COPRAS, Ekonomska istrazivanja - Economic Research 24(4): 27-40.

Ye, F. 2010. An extended TOPSIS method with interval-valued intuitionistic fuzzy numbers for virtual enterprise partner selection, Expert Systems with Applications 37(10): 7050-7055. http://dx.doi.org/10.1016/j.eswa.2010.03.013

Zadeh, L. A. 1965. Fuzzy sets, Information and Control 8(3): 338-353. http://dx.doi.org/10.1016/S00199958(65)90241-X

Zavadskas, E. K.; Turskis, Z. 2011. Multiple criteria decision making (MCDM) methods in economics: an overview, Technological and Economic Development of Economy 17(2): 397-427. http://dx.doi.org/10.3846/20294913.2011.593291

Zavadskas, E. K.; Kaklauskas, A.; Sarka, V. 1994. The new method of multicriteria complex proportional assessment of projects, Technological and Economic Development of Economy 1(3): 131-139.

Zavadskas, E. K.; Kaklauskas, A.; Peldschus, F.; Turskis, Z. 2007. Multi-attribute assessment of road design solution by using the COPRAS method, The Baltic Journal of Road and Bridge Engineering 2(4): 195-203.

Zavadskas, E. K.; Turskis, Z.; Tamosaitiene, J.; Marina, V. 2008. Multicriteria selection of project managers by applying grey criteria, Technological and Economic Development of Economy 14(4): 462-477. http://dx.doi.org/10.3846/1392-8619.2008.14.462-477

Zavadskas, E. K.; Kaklauskas, A.; Turskis, Z.; Tamosaitiene, E. J. 2009. Multi-attribute decision-making model by applying grey numbers, Informatica 20(2): 305-320.

Zhao, H.; Xu, Z.; Ni, M.; Liu, S. 2010. Generalized aggregation operators for intuitionistic fuzzy sets, International Journal of Intelligent Systems 25(1): 1-30. http://dx.doi.org/10.1002/int.20386

Zimmerman, H. J. 1987. Fuzzy sets, decision making, and expert systems. Boston: Kluwer Academic Publishers. http://dx.doi.org/10.1007/978-94-009-3249-4

Seyed Hossein RAZAVI HAJIAGHA. BSc in Industrial Engineering from Islamic Azad University in 2005. MA in Industrial management from Allame Tabatabaei University in 2007. Has worked as a researcher at the Institute of Trade Studies and Researches since 2008. PhD from the same university in 2012. Research interests: operation research and decision making methods under uncertainty. Has taught operation research at Allame University since 2009. Has published some papers in these areas.

Shide Sadat HASHEMI. BSc in Industrial management from Damavand University in 2004. MA in Industrial management from Allame Tabatabaei University in 2008. Has worked as a researcher since 2009. Research interests: operation management and data envelopment analysis.

Edmundas Kazimieras ZAVADSKAS. Prof., the Head of the Department of Construction Technology and Management at Vilnius Gediminas Technical University, Lithuania. PhD in Building Structures (1973). Dr Sc. (1987) in Building Technology and Management. A member of Lithuanian and several foreign Academies of Sciences. Doctore Honoris Causa from Poznan, Saint-Petersburg and Kiev universities. A member of international organizations; a member of steering and programme committees at many international conferences; a member of the editorial boards of several research journals; the author and co-author of more than 400 papers and a number of monographs in Lithuanian, English, German and Russian. Research interests: building technology and management, decision-making theory, automation in design and decision support systems. 